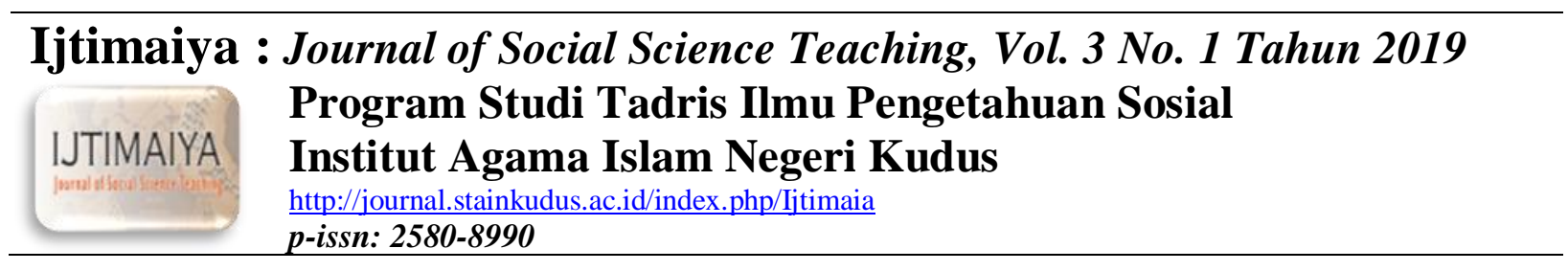

\title{
Pengaruh dan Relevansi Gusjigang bagi Peradaban Islam di Kudus
}

\author{
Dany Miftah M.Nur ${ }^{1}$ Ahmad Farohi ${ }^{2}$

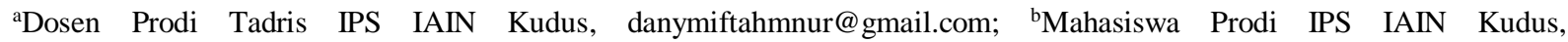 \\ ahmadfarohiey@gmail.com
}

\begin{tabular}{|c|c|}
\hline $\begin{array}{l}\text { Informasi } \\
\text { artikel }\end{array}$ & ABSTRACT \\
\hline $\begin{array}{l}\text { Sejarah artikel: } \\
\text { April } 2019 \\
\text { Mei } 2019 \\
\text { Juni } 2019 \\
\text { Keyword: } \\
\text { Gusjigang; } \\
\text { Moderation; } \\
\text { Islam; } \\
\text { Sunan Kudus }\end{array}$ & $\begin{array}{l}\text { Sayyid Ja'far Sodiq or known as Sunan Kudus is a figure who has an important role in the } \\
\text { entry of Islam in Kudus. The multicultural Holy Society has a unique typology in morals, } \\
\text { science and economics, known as "Gusjigang", Bagus-having good behavior), Ji (Ngaji- } \\
\text { good at reciting the Qur'an) and Gang (Dagang -good at trading). The identity crisis brings } \\
\text { human consciousness to explore the wealth, wisdom and excellence contained in local } \\
\text { culture, build and strengthen the identity and pride of the nation. Modernization or more } \\
\text { accurately said as Westernization on the one hand is able to achieve rapid progress, but on } \\
\text { the other hand it fails to achieve prosperity for nature and humans. This study reveals the } \\
\text { influence and relevance of Gusjigang from Kanjeng Sunan Kudus in moderating Islam in } \\
\text { Kudus in life with a unique format and typology that is able to become a new concept for } \\
\text { the development of morals, science and economics (trade) so as to create a prosperous and } \\
\text { prosperous society. }\end{array}$ \\
\hline
\end{tabular}

\begin{abstract}
ABSTRAK
Keyword:

Gusjigang;

Moderasi;

Islam;

Sunan Kudus

Sayyid Ja'far Sodiq atau dikenal dengan sebutan Sunan Kudus merupakan seorang figur yang mempunyai peranan penting dalam masuknya agama Islam di Kudus. Masyarakat Kudus yang multikultural memiliki tipologi unik dalam akhlak, ilmu dan perekonomian, yang dikenal dengan istilah "Gusjigang", kepanjangan dari bagus, ngaji, dan dagang. Krisis identitas membawa kesadaran manusia untuk menggali kembali kekayaan, kearifan dan keunggulan yang terkandung pada kebudayaan lokal (local wisdom), membangun dan memperkuat jati diri dan kebanggaan bangsa. Modernisasi atau lebih tepat dikatakan sebagai Westernisasi disatu sisi mampu mencapai kemajuan yang pesat, namun disisi lain gagal mencapai kesejahteraan untuk alam dan manusia. Penelitian ini mengungkap pengaruh serta relevansi Gusjigang dari Kanjeng Sunan Kudus dalam moderasi Islam di Kudus dalam kehidupan dengan format dan tipologi unik yang mampu menjadi konsep baru untuk pengembangan akhlak, ilmu pengetahuan serta perekonomian (berdagang) sehingga terciptanya masyarakat yang makmur dan sejahtera
\end{abstract}




\section{Pendahuluan}

Indonesia dengan keanekaragaman budaya, agama, suku, bahasa yang dimilikinya mentasbihkan dirinya sebagai salah satu bangsa yang memiliki masyarakat multikultural, keanekaragaman tersebut menjadi sebuah rahmat tersendiri bagi bangsa Indonesia jika dapat dikelola dengan baik, bahkan menjadi keunikan dan kekuatan tersendiri (Darlis, 2016: 111-140). Quraish Shihab mengatakan, bahwa "keanekaragaman dalam kehidupan merupakan keniscayaan yang dikehendaki Allah., termasuk dalam hal ini perbedaan dan keanekaragaman pendapat dalam bidang ilmiah, bahkan keanekaragaman tanggapan manusia menyangkut kebenaran kitab-kitab suci, penafsiran kandungannya, serta bentuk pengamalannya" (Quraish, 2007: $52)$.

Moderasi adalah ajaran inti agama Islam. Islam moderat adalah paham keagamaan yang sangat relevan dalam konteks keberagaman dalam segala aspek, baik agama, adat istiadat, suku dan bangsa itu sendiri. Keragaman tersebut, salah satunya, disebabkan oleh dialektika antara teks dan realitas itu sendiri, dan cara pandang terhadap posisi akal dan wahyu dalam menyelesaikan satu masalah (Quraish, 2007: 231).

Sejak kedatangan Islam di bumi Indonesia, sepanjang menyangkut proses penyebarannya sebagai agama dan kekuatan kultur. Dalam konteks ini, Islam disebarkan dengan cara damai, tidak memaksa pemeluk lain untuk masuk agama Islam, menghargai budaya yang tengah berjalan, dan bahkan mengakomodasikannya kedalam kebudayaan lokal tanpa kehilangan identitasnya. Ternyata sikap toleran inilah yang banyak menarik simpatik masyarakat Indonesia pada saat itu untuk mengikuti ajaran Islam. Sementara itu, walisongo adalah arsitek yang handal dalam pembumian Islam di Indonesia.

Menurut catatan Abdurrahman Mas'ud, walisongo merupakan agen-agen unik Jawa pada abad XV-XVI yang mampu memadukan aspek-aspek spiritual dan sekuler dalam menyiarkan Islam. Posisi mereka dalam kehidupan sosiokultural dan religius di Jawa begitu memikat hingga bisa dikatakan Islam tidak pernah menjadi the religion of Java jika sufisme yang dikembangkan oleh walisongo tidak mengakar dalam masyarakat. Berdasarkan fakta sejarah, bahwa dengan cara menoleransi tradisi lokal serta memodifikasinya ke dalam ajaran Islam dan tetap bersandar pada prinsip-prinsip Islam, agama baru ini dipeluk oleh bangsawanbangsawan serta mayoritas masyarakat Jawa di pesisir utara (Abdurrahman, 2006: 54).

Dalam "pribumisasi Islam" tergambar bagaimana Islam sebagai ajaran yang normatif berasal dari Tuhan diakomodasikan kedalam kebudayaan yang berasal dari manusia tanpa kehilangan identitasnya masing-masing. Dengan demikian, Islam akan mampu terus memperbaharui diri dan dinamis dalam merespon perubahan zaman (Imdadun, 2003: 41).

Sunan Kudus menjadi tokoh sentral dalam penyabaran agama Islam di Kudus dengan cara mengakulturasikan budaya Jawa, Hindu tanpa menghilangkan esensi ajaran agama Islam serta dengan semboyan Gusjigang yang berhasil mengubah peradaban di Kudus menjadi bermartabat akhlak, ilmu serta jiwa enterpreunership.

\section{Metode}

Penelitian ini menggunakan pendekatan dan jenis penelitian kualitatif. Pendekatan kualitatif bertujuan untuk mendapatkan pemahaman yang sifatnya umum terhadap kenyataan sosial dari perspektif partisipan (Purnomo, 2010:6). Peneliti menggunakan pendekatan ini karena ingin memahami lebih dalam tentang pelaksanaan pendidikan karakter peduli sosial dalam pembelajaran IPS. Penelitian dilaksanakan di SMP Negeri 1 Karangtengah yang terletak di Jalan Sultan patah Buyaran, Katonsari Karangtengah Demak pada tahun pelajaran 2017/2018. Hal menarik yang terdapat dalam sekolah ini yaitu adanya pembiasaan

Subjek dalam penelitian ini adalah guru IPS, Kepala Sekolah, dan siswa kelas VIII 
SMP Negeri 1 Karangtengah. Sumber data penelitian ini diperoleh dari data informan, kenyataan lapangan dan dokumen-dokumen. Teknik pengumpulan data menggunakan observasi tidak terstruktur, wawancara tidak terstruktur dan dokumentasi. Analisis data menggunakan analisis Miles dan Huberman. Uji keabsahan data penelitian ini dengan cara triangulasi yaitu pengecekan data dari berbagai sumber dan waktu.

Fokus penelitian ini adalah Implementasi pendidikan karakter peduli sosial dalam pembelajaran IPS. Penelitian ini juga meliputi budaya sekolah dalam mengimplementasikan pendidikan karakter peduli sosial di SMP Negeri 1 Karangtengah. selain kedua fokus penelitian tersebut, penelitian ini juga mengkaji hambatan dalam implementasi pendidikan karakter peduli sosial dalam pembelajaran IPSdi SMP Negeri 1 Karangtengah.

Sumber data penelitian terdiri dari informan utama dan informan pendukung. Informan utama penelitian ini merupakan guru IPS dan peserta didik SMP Negeri 1 Karangtengah yang memenuhi data dalam penelitian. Guru IPS yang dijadikan sebagai informan bernama Ibu Sofiyatun, S.Pd., hal ini karena guru IPS sebagai pelaksana kegiatan pembelajaran IPS di kelas lebih memahami bagaimana mengimplementasikan karakter peduli sosial dalam proses pembelajaran IPS. Sementara informan pendukung yang akan memberikan informasi-informasi tambahan data penelitian adalah Kepala Sekolah dan Waka Kurikulum. Sumber pendukung tersebut dipilih karena dipercaya dan mengetahui fokus penelitian secara mendalam, sehingga bisa membantu peneliti dengan memberikan keterangan yang ada di lapangan. Pengumpulan data dilakukan pada tanggal 31 Januari 2018 sampai 27 Maret 2018.

Penelitian ini menggunakan 3 sumber data, yakni (1) Informan, (2) Objek, dan (3) dokumen. Informan yang digunakan dalam penelitian ini adalah (a) Guru mata pelajaran IPS yaitu Ibu Sofiyatun, S.Pd. (b) Kepala Sekolah SMP Negeri 1 Karangtengah, yaitu
Ibu Sri Titik Cahyaningsih, S.Pd., M.Pd. (c) Waka Kurikulum yaitu Ibu Sri Hari, S.Pd., (d) Perwakilan siswa-siswi SMP Negeri 1 Karangtengah yaitu Tina, Gigih, Alvin, Lutfi, dan Salsabila. Dokumen yang digunakan dalam penelitian berupa RPP, dokumentasi pembelajaran dan budaya sekolah. Dokumendokumen tersebut dipilih dan digunakan yang sesuai dalam penelitian..

\section{Hasil dan Pembahasan}

Kudus adalah sebuah kabupaten di Provinsi Jawa Tengah. Kudus dikenal sebagai kota penghasil rokok (kretek). Kabupaten Kudus pada saat ini berpenduduk 802.277 jiwa, dengan penganut agama Islam yang mayoritas 785.388 jiwa, dibanding dengan Protestan 13.062 jiwa, Katolik 3.353, Hindu 73 jiwa, Budha 400 jiwa dan 1 jiwa beragama lainnya (Badan Pusat Statistik Provinsi Jawa Tengah, Update Terakhir 14 Agustus 2018). Kabupaten Kudus merupakan salah satu kabupaten "terkecil" di Jawa Tengah dan hanya memiliki luas wilayah $\pm 42.517 \mathrm{~km}^{2}$ (menurut data BPS 2015), tetapi menjadi kota industri yang memiliki berbagai jenis perusahaan serta menjadi sentra ekonomi kecil dan menengah yang mampu berkembang pesat seiring dengan denyut nadi perekonomian masyarakat (Mustaqim, 2015: 22).

Salah satu ragam kebudayaan Jawa di sepanjang pantai Utara dikenal sebagai kebudayaan Pesisir. Kebudayaan Pesisir merupakan kebudayaan Jawa yang berkembang di kota-kota di sepanjang pantai Utara pulau Jawa. Beberapa Kawasan dipengaruhi aktivitas perdagangan serta penyebaran agama Islam. Masyarakat Pesisir dikenal mempunyai karakter egaliter, terbuka dan lugas. Hal ini berkaitan dengan kehidupan mereka sebagai pedagang yang memandang orang lain sederajat serta faham keagamaan (Islam) yang menekankan pada konsep kesejajaran (Thohir, 1999: 2).

Pada daerah Pesisir Timur dalam sejarahnya terdapat tiga kota yang cukup terkenal yakni : Demak, Jepara serta Kudus. Demak merupakan pusat kekuasaan kerajaan 
Demak Bintoro. Jepara merupakan kota pelabuhan penting bagi kerajaan Demak, sementara Kudus merupakan kota pemasok hasil bumi untuk Demak dan Jepara yang didatangkan dari pedalaman. Demak, Kudus dan Jepara mempunyai keterkaitan sejarah yang erat, baik dalam hubungan pemerintahan, pernikahan, perdagangan maupun pengembangan agama Islam (De Graaf \& Pigeaud, 1985:126).

Secara geografis Kudus lebih banyak dipengaruhi oleh Islam pesisir karena memang diapit oleh sejumlah kota pesisir yang saling menyatu sehingga dikenal dengan sebutan "Anak Wedus Mati Ketiban Berang" (Demak, Kudus, Pati, Rembang). Diantara karakter masyarakat pesisir adalah (coastal area) keterbukaan, egaliter, dan mobilitas yang tinggi sehingga mudah menerima perubahanperubahan serta akomodatif dalam berinteraksi dengan budaya lokal (Nur Syam, 2005: 277; Nur Said, 2010: 148).

Kudus merupakan salah satu pusat kebudayaan Pesisir di bagian Timur atau Pesisir Wetan (Koentjaraningrat, 1984: 56), sekalipun Kudus tidak terletak di daerah pantai dan bukan kota pelabuhan. Kudus juga dikenal sebagai salah satu pusat pengembangan agama Islam di pantai Utara Jawa (Salam, 1977: 51; De Graaf \& Pigeaud, 1985: 120-122). Secara sosiologis kota Kudus terbagi menjadi dua yakni Kudus kulon dan Kudus wetan yang dipisahkan oleh sungai (kali) Gelis. Kudus kulon adalah kota lama yang dikonotasikan dengan kekunoan, kekolotan, ketertutupan tetapi juga kesalehan serta kemakmuran. Sedangkan Kudus wetan dikenal sebagai daerah perkembangan yang lebih modern, lebih heterogen serta daerah yang sekuler (Castles, 1982:78-79).

Lance Castle (1982 : 88-89) dalam risetnya di Kudus memetakan tiga golongan masyarakat di Kudus yaitu; pertama, golongan pegawai, yaitu mereka yang meniru cara hidup pegawai seperti guru, dokter dan pejabat pemda dan sejenisnya; kedua, golongan pedagang (wong dagang) dengan berbagai produk industri rumahan atau pabrikan; ketiga, golongan wong cilik termasuk buruh, pelayan rumah tangga dan para penganggur termasuk petani di lingkungan kampung. Dalam konteks masyarakat Kudus Kulon yang banyak dipengaruhi oleh misi dakwah Sunan Kudus termasuk golongan santri pedagang atau dikenal dengan santri saudagar (Nur Said, 2010: 148).

Masyarakat Kudus kulon dikenal sebagai masyarkat religius, kehidupan keagamaannya mendominasi kehidupan sehari-hari, disisi lain mereka dikenal sebagai pedagang yang gigih, pekerja keras dan terampil. Dari sinilah masyarakat Kudus mendapat predikat sebagai masyarakat Santri Pedagang. Santri secara kultural merupakan sebutan atau artikulasi dari istilah masyarakat agamis yakni masyarakat muslim yang saleh. Budaya Santri menggambarkan tata kehidupan masyarakat yang erat dengan nuansa Islam. Diantara mereka dikenal ungkapan Gusjigang yang berarti Bagus akhlaknya, pandai meNgaji (membaca, mempelajari Al-Quran) dan terampil ber Dagang. Ngaji adalah aktivitas keagamaan yang mencerminan ketaatan seorang muslim dalam menjalankan perintah agama, sedangkan Dagang adalah upaya manusia memenuhi kebutuhan hidupnya di dunia. Kegiatan duniawi dan ukhrowi harus dijalankan secara seimbang agar tercapai kebahagiaan di dunia dan di akhirat. Bagi masyarakat Kudus kulon Ngaji dan Dagang merupakan satu kesatuan sikap yang diteladani dari Nabi Muhammad SAW serta Sunan Kudus, dua tokoh keagamaan yang sangat dihormati di kalangan masyarakat Kudus.

Di Kudus Kulon terletak salah satu peninggalan bukti penyebaran agama Islam, yakni Menara Masjid Kudus. Menara masjid ini terdapat Masjid Al Aqsha dan di belakang masjid terdapat kompleks makamyang dikelilingi rumah penduduk yang padat sekali, diantaranya banyak terdapat rumah-rumah adat yang disebut "Pencu". Di sekitar rumah penduduk diselingi jalan sempit yang berfungsi sebagai batas rumah penduduk dan sekarang menjadi jalan umum. Jelas hal tersebut masih memperlihatkan ciri 
perkampungan kuno. Kota Kudus juga merupakan sentra perekonomian di Jawa Tengah Utara. Hal ini terbukti dengan banyaknya perusahaan besar dan kecil seperti industri rokok, batik, percetakan, pertenunan dan keramik dan perusahaan industri tersebut sampai sekarang masih berdiri (Badan Pusat Statistik Provinsi Jawa Tengah, Update Terakhir 14 Agustus 2018).

Dilihat dari peninggalan-peninggalan yang ada seperti Menara Masjid Kudus yang bersifat kuno. Bagi penduduk Kudus sifat Animisme dan Dinamisme ini tampaknya tidak berubah, malah bertambah dengan timbulnya suatu akulturasi. Tampak misalnya pada upacara Buka Luwur (penggantian kelambu makam), seperti di Makam Sunan Kudus. Orang-orang berdatangan dengan berbagai maksud, ada yang ingin mendapatkan sobek kain Luwur untuk jimat, atau ada pula mengharap mendapatkan sebungkus nasi. Kemudian nasi itu dikeringkan lalu ditaburkan di ladang agar subur.

Ketika Islam masuk ke Jawa, banyak unsur Hindu yang masuk ke dalam Islam. Dari segi arsitektur misalnya, tampak pada bangunan Menara Masjid Kudus dan bangunan-bangunan lain di kompleks Mesjid Kudus. Seperti atap tumpang bertingkat tiga yang menutupi masjid, bangunan gapura yang mengelilingi atau terdapat pada tembok penutup kompleks, yang semuanya mirip dengan pola arsitektur Hindu seperti pada bangunan-bangunan suci di Bali. Orang Hindu memuja sapi, hingga merasa tabu memotong sapi, tetapi makan dagingnya diperbolehkan. Daging yang dimakan, mereka datangkan dari luar Kudus seperti Jepara, Pati dan sebagainya. Dengan demikian dapat dikatakan, bahwa di Kudus dan sekitarnya unsur-unsur toleransi terhadap Ajaran Hindu masih kuat.

Menara Kudus adalah bangunan peninggalan Sunan Kudus hasil dari akulturasi dalam penyiaran agama Islam antara kebudayaan Hindu, Jawa dengan Islam. Unsur Islam yang terlihat yaitu ornamen yang serba sederhana. Sedangkan unsur Indonesia tampak di hiasan tumpalnya. Bagian puncak menara berupa ruangan mirip pendopo berlantaikan papan. Cara Sunan Kudus menyiarkan agama Islam seperti halnya para wali yang lain yaitu dengan kebijaksanaan, tidak dengan kekerasan atau paksaan. Dengan cara demikian Sunan Kudus mengajarkan agama Islam kepada mereka, dan lambat laun dengan kemauannya sendiri para penganut agama Hindu ini kemudian masuk Islam. Sebagai wali yang menaruh perhatian dalam kesusasteraan, diceritakan bahwa Sunan Kudus juga menciptakan Gending Maskumambang dan Mijil (Badan Pusat Statistik Provinsi Jawa Tengah, Update Terakhir 14 Agustus 2018).

\section{Makna Gusjigang}

Istilah gusjigang sangat populer, terutama bagi warga kudus yang tinggal di sebelah barat kudus, tepatnya di sekitar area Menara Kudus. Sampai detik ini, belum ada yang mengetahui kapan tepatnya istilah gusjigang muncul. Gusjigang merupakan singkatan dari 3 buah kata, yaitu gus, berasal dari kata bagus, ji berasal dari kata ngaji, dan gang berasal dari kata dagang (Nur, 2014: 230).

Gusjigang (bagus, ngaji, dagang) selama ini diyakini sebagian orang sebagai citra diri masyarakat Kudus. Filosofi ini merupakan warisan budaya yang konon dicetuskan oleh Sunan Kudus sebagai peletak dasar Kudus. Gusjigang mengisyaratkan bahwa tapak laku Muslim itu haruslah bagus (baik), bisa mengaji, dan pandai berdagang. Ada semacam integritas antara perilaku agama dan pekerjaan, yang ketiga hal tersebut tentu saja menjadi karakter bagi setiap manusia (Mustaqim, 2015: 21).

Ajaran yang ditanamkan sunan kudus telah membawa pengaruh besar bagi warga kudus, khususnya warga di sekitar masjid Al-Aqsha yang kini dikenal dengan kudus kulon sebagai masyarakat agamis yang pandai berdagang. Keberadaan masjid yang berdekatan dengan pasar ini semakin memperkuat prinsip gusjigang. Masjid $\mathrm{Al}$ Aqsha merupakan masjid yang di bangun oleh sunan kudus, masjid yang kemudian mejadi sentra nadi kehidupan masyarkat kudus. 
Bangunan masjid memadukan arsitektur jawa, islam, hindu, dan china yang kemudian menjadi saksi sekaligus pengikat abadi berkembangnya filosofi sunan kudus, yaitu gusjigang (Sri, 2016: 164).

\section{a. Gus (Bagus)}

Gus (Bagus) berarti bagus dalam hal apa saja seperti dalam bersikap, berakhlak maupun sopan santun. Dalam perspektif Islam, akhlak atau moral memiliki kedudukan yang tinggi. Demikian tingginya kedudukan akhlak dalam Islam hingga Nabi shallallahu ,alaihi wasallam menjadikannya sebagai barometer keimanan. Beliau bersabda: "Orang mukmin yang paling sempurna imannya adalah yang paling baik akhlaknya." (HR. Abu Dawud dan Tirmidzi). Akhlak Islami memiliki beberapa keistimewaan dan ciri-ciri khusus (karakteristik) yang membedakannya dari sistem akhlak lainnya (Ibrahim, 2011: 45).

\section{b. Ji (Ngaji)}

Salah satu ciri yang membedakan Islam dengan yang lainnya adalah penekanannya terhadap ilmu. Al-Qur'an dan As-Sunnah mengajak kaum muslimin untuk mencari dan mendapatkan ilmu dan kearifan, serta menempatkan orang-orang yang berpengatahuan pada derajat yang tinggi. Beberapa ayat Al-Qur'an yang diwahyukan pertama kepada Nabi Muhammad SAW., menyebutkan pentingnya membaca bagi manusia. Sebagaimana dijelaskan dalam Q.S. al-Alaq ayat 1-5.

\section{c. Gang (Dagang)}

Dagang adalah kata ketiga dari gusjigang. Seringkali, kesuksesan sebuah dagang atau bisnis hanya dilihat dari seberapa besar profit yang diperoleh dari bisnis tersebut (Danang, 2013: 1). Karakter Gusjigang pengusaha Kudus sangat tampak dalam perilaku keseharian mereka (Ihsan, 2017: 170).

Hasil dari tindakan keberagamaan tepat dan relevan ini akan mengantarkan manusia pada jati dirinya yang tangguh, serta memiliki jiwa sosial yang tinggi pula. Secara vertikal akan mengantarnya pada kepada
Allah, dan secara horizontal akan menghasilkan ketaqwaan. Spirit Gusjigang juga bisa menjadi cambuk agar menjalankan suatu bisnis atau usaha harus sesuai dengan ajaran Islam. Jika spirit ini bisa ditanamkan dengan baik dalam masyarakat, maka secara otomatis akan meminimalisir terjadinya usaha yang menghalalkan segala cara.

2. Pengaruh Ajaran Gusjigang Dalam Moderasi Islam

Dalam perjalanan penyiaran agama Islam yang dilakukan Sunan Kudus melakukan dan mengajarkan suatu ajaran yang disebut Gusjigang. Dengan menerapkan Gusjigang di kehidupan, akan tercipta kehidupan yang harmonis dan tanpa ketegangan sosial. Yaitu terciptanya suatu toleransi dan integrasi saling memahami dan menghargai antar masyarakat. Hal yang demikian itu senada dengan Islam moderat atau moderasi Islam yang mengedepankan Islam yang tengah-tengah.

a. Pengaruh gusjigang sebagai perbaikan akhlak dan pembangunan karakter

Gus/ bagus akhlak. Akhlak berasal dari bahasa Arab jama' dari bentuk mufradatnya "khuluqun" yang berari budi pekerti, perangai, tingkah laku dan tabiat. Sedangkan menurut istilah adalah pengetahuan yang menjelaskan tentang baik dan buruk (benar dan salah), mengatur pergaulan manusia, dan menentukan tujuan akhir dari usaha dan pekerjaannya. Untuk itu Tradisi Gusjigang perlu ditanamkan melalui pendidikan karakter pada masyarakat Kudus.

Adapun hal-hal yang perlu dibiasakan sebagai akhlak yang terpuji dalam islam, antara lain:

1. Berani dalam kebaikan, berkata benar serta menciptakan manfaat, baik bagi diri maupun orang lain.

2. Adil dalam memutuskan hukum tanpa membedakan kedudukan, status sosial ekonomi, maupun kekerabatan.

3. Arif dan bijaksana dalam mengambil keputusan.

4. Pemurah dan suka menafkahkan rezeki baik ketika lapang maupun sempit. 
5. Ikhlas dalam beramal semata-mata demi meraih ridha Allah.

6. Cepat bertobat kepada Allah ketika berdosa.

7. Jujur dan amanah.

8. Tidak berkeluh kesah dalam menghadapi masalah hidup.

9. Penuh kasih sayang.

10. Lapang hati dan tidak balas dendam

11. Malu melakukan perbuatan yang tidak baik.

12. Rela berkorban untuk kepentingan umat dan dalam membela agama Allah.

Ajaran Gusjigang utamanya

Gus/ bagus akhlak sangat berpengaruh pada moderasi Islam yang kaitannya dengan peradaban dan kemanusiaan. Maka tidak salah bahwa Gusjigang mampu memberikan sebuah ajaran untuk perbaikan kepribadian setiap masing-masing individu sehingga terciptanya kemanusiaan yang beradab dan berkarakter.

b. Pengaruh dari segi sosial kemasyarakatan Ji (ilmu )

Salah satu ciri yang membedakan Islam dengan yang lainnya adalah penekanannya terhadap ilmu (sains). Fungsi ilmu yang mencakup sikap dan perilaku orang-orang yang berilmu serta karakteristik mereka. Iman yang mencakup sikap dan perilaku orang terhadap Allah SWT dan ajaran-Nya

Berangkat dari ajaran makna gusjigang yang sangat erat hubungannya dengan ajaran islam. Ji (ngaji) mengajarkan manusia untuk sadar akan pentingnya ilmu pengetahuan, baik agama maupun umum, baik dunia maupun akhirat. Sunan Kudus mengajarkan masyarakat Kudus untuk selalu mengaji atau mencari ilmu. Buktinya sampai sekarang di wilayah Kudus masih menjadi pusat majelis keilmuan seperti banyak pondok pesantren, sekolah, Institut dan universitas yang berdiri, banyak para pemuda maupun pemudi dari luar daerah menimba ilmu agama di Kudus untuk memperdalam baik agama maupun ilmu umum lainnya. Ditambah pula Kudus masih dijuluki sebagai kota santri, karena banyak pemuda yang nyantri di pondok pesantren.

c. Pengaruh dalam segi perekonomian
Banyak orang yang menganggap bahwa Islam tidak memperhatikan aspek ekonomi. Keduanya (Islam dan ekonomi) dianggap sebagai hal yang bertentangan dan tidak akan pernah bertemu. Mereka menganggap ekonomi berhubungan dengan aspek materi dalam kehidupan, sementara agama mengurusi aspek rohani. Ekonomi berarti tenggelam dan larut dalam materi, sedangkan agama dilupakan dari hal itu. Kemudian Islam juga menganjurkan perdagangan. Islam menghargai seorang yang jujur (Ihsan, 2017: 43). Hal ini tentunya sesuai dengan ajaran gusjigang yang mengedepankan perdagangan sebagai penopang masyarakat kudus pada khususnya.

Jika Gusjigang diuraikan secara keseluruhan adalah seorang pedangang itu harus berakhlak baik, mulia, berperilaku baik, bermoral baik serta menjalankan usaha (berdagang) pun dengan cara baik dan beretika, berdasarkan aqidah Islam. Prinsipprinsip dalam berdagang adalah (1) kejujuran; (2) barokah atau mencari berkah; (3) keterbukaan; (4) membangun kepercayaan. Keempat prinsip ini akan dilihat implementasinya dalam produksi, distribusi dan konsumsi pada pengusaha/pedagang jenang, bordir, dan konveksi (Suminarsih, 2016: 104).

\section{Relevansi Ajaran Gusjigang Di Masa} Kini

Ajaran gusjigang merupakan suatu ajaran Sunan Kudus yang mengajarkan pentingnya akhlak yang baik. Gusjigang juga tidak dipahami sebagai sebuah norma saja, akan tetapi mesti diperlakukan sebagai sebuah "organisme" yang hidup, berkembang, dan mempengaruhi orang yang dihinggapi. Nilainilai tersebut tidak lagi diperlakukan sebagai pepatah suci yang hanya dihafalkan belaka, tapi benar-benar dipraktekkan dalam perilaku kongkrit sebagai bentuk religiusitas (Ihsan, 2017: 132). Ajaran ini telah ditanamkan melalui pendidikan karakter pada masyarakat Kudus.

Penerapan akhlak yang lebih ditekankan pada generasi muda karena generasi muda 
akan menjadi penerus bangsa yang memiliki akhlak mulia akan memajukan bangsa dan negara di masa mendatang. Jadi penerapan ini diharapkan dapat menciptakan masyarakat Kudus yang religius sesuai dengan sebutan Kota Kudus sebagai Kota Santri. Ji atau pintar mengaji merupakan singkatan dari mengaji. Mengaji, khususnya mengkaji kitab Islami untuk mengetahui bagaimana hubungan dengan Allah agar dapat mendekatkan diri kepada Allah. Di samping itu mengaji disini bukan hanya sekedar belajar kitab-kitab Islami, tetapi juga belajar berkehidupan dan bersosialiasi dengan sesama umat manusia. Dengan adanya mengaji yang diterapkan kepada masyarakat Kudus, maka akan menjadi pribadi yang cerdas.

Gang "berdagang". Berdagang merupakan salah satu ajaran yang diajarkan oleh Sunan Kudus kepada para pengikutnya untuk dapat bertahan hidup. Sosok Sunan Kudus dikenal sebagai saudagar / pengusaha ulet untuk mendukung misi dakwahnya menjadi pelopor dan teladan bagi masyarakat Kudus terutama di sekitar Kudus Kulon. Sunan Kudus adalah seorang pendatang baru yang datang ke Kudus untuk menyebarkan agama Islam kepada masyarakat Kudus. Beliau datang tidak hanya untuk menyebarkan agama Islam tetapi juga membangun karakter berdagang tidak hanya sekedar untuk bertahan hidup dan mencukupi kebutuhan duniawi, tetapi juga dapat diniatkan untuk ibadah kepada Allah SWT, sekaligus untuk mendukung dakwah pada saat itu (Ihsan, 2017: 175).

Falsafah Gusjigang yang diajarkan Sunan Kudus dalam membangun karakter masyarakat Kudus menjadi lebih baik merupakan salah satu aplikasi pemanfaatan nilai-nilai kearifan lokal sebagai basis pendidikan karakter. Guru, sebagai kunci dalam proses pembelajaran dan pendidikan diharapkan memiliki profil yang sesuai dengan karakter masyarakat dan sesuai dengan tuntutan perkembangan (Ihsan, 2017: 175).

Dengan pendidikan yang berbasis pada local wisdom (kearifan lokal) maka kita bisa optimis akan terciptanya pendidikan yang mampu memberi makna bagi kehidupan manusia Indonesia. Artinya pendidikan kemudian akan mampu menjadi spirit yang bisa mewarnai dinamika manusia Indonesia kedepan. Pendidikan nasional kita harus mampu membentuk manusia yang berintegritas tinggi dan berkarakter sehingga mampu melahirkan anak-anak bangsa yang hebat dan bermartabat sesuai dengan spirit pendidikan yaitu memanusiakan manusia (Ihsan, 2017: 176).

Kota Kudus dikenal sebagai kota Kretek yakni kota akan sejuta industri rokok yang telah mengantarkan Kota Kudus dalam kancah nasional. Tidak hanya rokok, perekonomian masyarakat Kudus juga berkembang dari usaha konveksi, gula, beras, jenang dan masih banyak lagi. Oleh karena itu, konsep tersebut sangat penting untuk diterapkan oleh masyarakat Kudus. Gusjigang juga dapat mengajarkan seorang tidak hanya pandai berdagang untuk mencari keuntungan semata, tetapi pandai berdagang di jalan Allah SWT.

Maka tidak bisa dibantahkan bahwa ajaran gusjigang masih relevan bagi kehidupan masyarakat masa kini yang sangat cocok untuk menjadi spirit dalam menghadapi problema kehidupan, seperti penerapan akhlak, karakter, ilmu pengetahuan serta relevanannya terhadap dunia enterpreuner (berdagang)/wirausaha. Hal ini tercermin dalam budaya masyarakat Kudus yang masih memegang teguh falsafah leluhurnya, sehingga mengantarkan mereka pada sebuah keberhasilan. Gusjigang sebagai tradisi santri-muslim yang taat, dan tradisi ekonomi perdagangan dan industri, merupakan fenomena yang mampu menjadikan ekonomi masyarakaat Kudus berkembang pesat (Ihsan, 2017: 178).

\section{Simpulan}

Sunan Kudus adalah salah satu walisongo yang menyebarkan Islam di Daerah Kudus. Dalam penyebarannya beliau menggunakan kesenian dengan menciptakan Gending Maskumambang, Mijil serta telah 
mendirikan Menara Masjid Kudus, arsitektur Masjid mengakulturasi budaya Hindu dan Islam. Akulturasi budaya ini menciptakan toleransi antara budaya yang sudah ada, sehingga Islam dapat diterima dengan baik.

Beliau juga mengajarkan ajaran Gusjigang yaitu Gus (Bagus akhlaknya), Ji (Mengaji), Gang (Dagang). Ajaran ini mengisyaratkan bahwa tapak laku muslim itu haruslah bagus atau baik, bisa mengaji dan pandai berdagang. Penerapan Gusjigang diharapkan dapat meningkatkan spiritualitas dan menata basis ekonomi warga Kudus. Maka tidak bisa dibantahkan bahwa ajaran gusjigang masih relevan bagi kehidupan masyarakat masa kini yang sangat cocok untuk menjadi spirit dalam menghadapi problema kehidupan, seperti penerapan akhlak, karakter, ilmu pengetahuan serta relevanannya terhadap dunia enterpreuner (berdagang)/wirausaha

\section{Referensi}

Adaby Darban, Ahmad. 1984. Fragmenta Sejarah Islam di Indonesia. Yogyakarta: Pustaka Irma

Badan Pusat Statistik Provinsi Jawa Tengah. 2018. Update Terakhir 14 Agustus.
Castle, Lance. 1982. Tingkah Laku Agama, Politik dan Ekonomi di Jawa: Industri Rokok Kretek Kudus, Penterjemah: J.Sirait, S.Th., Jakarta: Sinar Harapan.

Darlis. 2016. Peran Pesantren As'adiyah Dalam Membangun Moderasi Islam di Tanah Bugis, Al-Misbah; Volume 12 Nomor 1.

Graaf \& Pigeaud, 1985, Kerajaan-Kerajaan Islam di Jawa, Peralihan dari Majapahit ke Mataram, Jakarta : Grafitipers.

Ibrahim, F. A. and C. Dykeman. (2011). Counseling Muslims Americans: Cultural and Spiritual Assessment. Journal of Counseling and Development, 89 (4),387396.

Ihsan, M. 2017. Gusjigang; Karakter Kemandirian Masyarakat Kudus Menghadapi Industrialisasi. Iqtishadia. Volume 10 Nomer 2.

Koentjaraningrat. 1984. Kebudayaan Jawa. Jakarta : Balai Pustaka

Mas'ud, Abdurrahman. 2004. Intelektual Pesantren; Perhelatan Agama dan Tradisi, Yogyakarta: LKiS

Mas'ud, Abdurrahman. 2006. Dari Haramain Ke Nusantara: Jejak Intelektual Arsitek Pesantren. Jakarta: Kencana.

Mulyani, Sri. 2016. Peran Gusjigang Dan Penerapan Akuntansi Terhaap Literasi Keuangan Pra-Nikah, Jurnal Dinamika Ekonomi Dan Bisnis. Volume 122. Nomor 2.

Mustaqim, Muhammad, Dan Ahmad Bahruddin. 2015. Spirit Gusjigang Kudus Dan Tantangan Globalisasi Ekonomi. Jurnal Penelitian, Vol. 9, No. 1. 